East African Medical Journal Vol. 86 No. 6 June 2009

MOLECULAR TYPING AND ANTIBIOTIC SUSCEPTIBILITY PATTERNS OF ENTEROPATHOGENIC AND SHIGATOXIN PRODUCING ESCHERICHIA COLI ISOLATED FROM FOOD HANDLERS IN THREE AREAS OF KENYA

J.O. Oundo, PhD, Resident Advisor, Deputy laboratory Director, Field Epidemiology and Laboratory Training Programme, Kenya Medical Research Institute, Centre for Microbiology Research, P. O. Box 19464-00202, Nairobi, Kenya, Y. Iijima, $\mathrm{PhD}$, Vice Director, Department of Microbiology, Kobe Institute of Health, 4-6 Minatojima-Nakamachi, Chuo-Ku, Kobe 650-0046, Japan, H. I. Boga, PhD, Principal, Taita-Taveta Campus, Jomo Kenyatta University of Agriculture and Technology, P. O. Box 62000-00100, Nairobi, Kenya, F. Muli, PhD, Associate Professor, Department of Biochemistry, Kenyatta University, P.O. Box 43844, Nairobi, Kenya and S. Kariuki, BVM, MSc, PhD, Chief Research Officer, Kenya Medical Research Institute, Centre for Microbiology Research, P. O. Box 19464-00202, Nairobi, Kenya

Request for reprints to: Dr. J.O. Oundo, Kenya Medical Research Institute, Centre for Microbiology Research, P. O. Box 19464-00202, Nairobi, Kenya

\title{
MOLECULAR TYPING AND ANTIBIOTIC SUSCEPTIBILITY PATTERNS OF ENTEROPATHOGENIC AND SHIGATOXIN PRODUCING ESCHERICHIA COLI ISOLATED FROM FOOD HANDLERS IN THREE AREAS OF KENYA
}

\author{
J.O. OUNDO, Y. IIJIMA, H. I. BOGA, F. MULI and S. KARIUKI
}

\begin{abstract}
Objectives: To determine the aetiology, epidemiology and sanitary factors of carriage of enteropathogenic Escherichia coli (EPEC) and Shiga-toxin producing E. coli (STEC) in food-handlers working in tourist hotels in three popular tourist destinations in Kenya.

Design: Cross sectional laboratory based study.

Setting: Three tourist destinations of Nairobi, Malindi and Diani in Kenya.

Subjects: Food handlers who were working in hotels frequented by tourists in the three study sites.

Results: Overall, during the period of April 2003 to May 2004, a total of 1399 food handlers stool samples were collected and analysed. EPEC expressing the eaeA gene and STEC expressing the stx 2 gene were detected in $11 / 1399(0.8 \%)$ and 2/1399 $(0.1 \%)$ of the study subjects respectively. The mean age of the subjects from whom EPEC and STEC were isolated was similar (32.6 years) to those from whom no EPEC and STEC were isolated (32.5 years). Prior use of antibiotics, water source and toilet types were not significantly associated with the isolation of EPEC and STEC $(p>0.05)$. There were 11 resistance patterns with six isolates $(6 / 13,46.2 \%)$ showing multidrug resistance. High prevalence of resistance was observed to co-trimoxazole $(55.6 \%)$, chloramphenicol (33.3\%), ampicillin (22.2\%) and tetracycline $(22.2 \%)$. High concentrations of antibiotics were required to achieve $\mathrm{MlC}_{90}$ for tetracycline, $\left(>64 \mathrm{mg} \mathrm{ml}^{-1}\right)$ and ampicillin $(>256 \mathrm{mg}$ $\mathrm{ml}^{-1}$ ). Cluster analysis of the Pulse Field Gel Electrophoresis profiles revealed that the EPEC and STEC isolates belonged to two main genotypes with 11 distinct DNA fragment profiles.

Conclusion: This is the first report in Africa on the isolation of STEC from food handlers working in tourist hotels. These food handlers who carry the STEC and EPEC could potentially infect tourists and other people through food or water contamination in the hotel settings and thus our findings are of great public health importance.
\end{abstract}

\section{INTRODUCTION}

Infectious bacterial diarrhoea is increasingly common in travellers to tropical and subtropical countries (1) and affects about $40 \%$ of people travelling to these countries (2). The incidence of traveller's diarrhoea (TD) in various parts of the world has been reported to vary from $26 \%$ to over $50 \%$ (3-5). Food-borne illnesses which are commonly under reported (6-7) are the major causes of TD with about 76 million cases of illness and 325,000 hospitalisations reported annually in the United States alone (8). The bacterial pathogens causing theseinfections have been found to be multi-drug resistant especially those isolated from tourists (3). The possibility of hotel workers harbouring multi-drug resistant bacterial pathogens has not been investigated in Kenya. The presentstudy was designed to investigate the aetiology and epidemiology of 
enteropathogenic Escherichia coli (EPEC) and shigatoxin-producing Escherichia coli (STEC) isolated from food handlers working in touristhotels in threepopular tourist destinations in Kenya.

\section{MATERIALS AND METHODS}

Study sites: The study was carried out in Nairobi, Malindi and Diani, which are some of the main tourist destinations in Kenya. Nairobi with a population of about three million people is the capital city and has the main international airport used for the arrivals of the greater majority of tourists coming to Kenya (9). Malindi is a small, northern coastal town in Kenya with a population of about 53,805 (10) and is one of the major tourist destinations in Kenya. There is a high concentration of tourist hotels within the town and its environs. Tourism is the main economic activity in this town. Diani, with a population of about 50,000 people in the south coast of Kenya has a high concentration of tourist facilities especially along the beach areas of Diani.

Study population: The subjects were all adult food handlers working in tourist hotels in the three study areas of Nairobi, Malindi and Diani. For the purposes of this study, food handlers were defind as any person who was involved in any way with handling, processing and serving of food such as waiters, cooks, chefs, barmen, butchers and delivery people.

Stool samples collection and initial processing: Stool samples were collected in sterile wide mouth containers after obtaining informed written consent from the workers. The study was approved by the scientific steering committee of the Kenya Medical Research Institute (KEMRI) and the National Ethical
Review Committee.Socio-economicand demographic data on age, sex, water source, sanitation disposal, and antibiotic use in the preceding two weeks, and residence was also obtained from each individual. The stool samples from workers from Nairobi hotels were transported to the KEMRI, Centre for Microbiology Research laboratory in chilled boxes. These were processed within one hour of collection. For hotels in Malindi and Diani the stool samples were collected in containers as before and transported chilled to the KEMRI laboratories in Malindi and Diani for initial processing.

\section{Microbiological procedures}

Isolation and real-time PCR for identification of EPEC and STEC: Stool samples were inoculated onto MacConkey agar and incubated aerobically at $37^{\circ} \mathrm{C}$ for 18 to 24 hours. Five lactose fermenting colonies were picked at random from the MacConkey plateand inoculated into vials containing trypticase soy broth with $15 \%$ glycerol and kept at $-80^{\circ} \mathrm{C}$ until analysed. Other enteropathogens and enteroparasites were identified using standard microbiological methods.

Real-time PCR was done as previously described (11). Briefly, bacteria were grown on Luria-Bertani (LB) agar and suspended at a concentration of approximately $1 \times 10^{9} \mathrm{ml}^{-1}$ in Milli-Q water and boiled at $100^{\circ} \mathrm{C}$ for five minutes. After centrifugation at $10,000 \times \mathrm{g}$ for five minutes, the supernatants were diluted 10-fold with Milli-Q water and applied to the real-time PCR assay. Primers and TaqMan probes sequences to detect STEC and EPEC are shown in Table 1. Isolated STEC and EPEC were serotyped by anti-diarrhoegenic E. coli that recognises 50 serotypes (Denka Seiken, Tokyo, Japan).

Table 1

Primer and fluorogenic probe sequences for detection of EPEC and STEC

\begin{tabular}{llll}
\hline E. coli strain Gene & Sequence & $\left(5^{\prime}-3^{\prime}\right)$ \\
\hline STEC & & Forward & TCTCGACTGCAAAGACGTATGTAGA \\
& Reverse & TCCTGATGAAATAGTCTGTAATGGAGTAC \\
& Probe & FAM- TCGCTGAATGTCATTCGCTCTGCAATA- TAMRA \\
& Forward & ACCCCACCGGGCAGTT \\
& stx2 & Reverse & GGTCAAAACGCGCCTGATA \\
& Probe & FAM- TTTTGCTGTGGATATACGAGGGCTTGATGT- TAMRA \\
EPEC & Forward & TGTTGCTTTGTTAATTCYGATAAGC \\
& \multirow{2}{*}{ eaeA } & Reverse & GGAATCGGAGTATAGTTTACACCAA \\
& & Probe & FAM-AGTCGAATCCTGGTGCGGC-TAMRA
\end{tabular}


Determination of antibiotic minimum inhibitory concentrations: The minimuminhibitory concentration (MIC) of antibiotics against the test isolates were determined by the agar dilution technique as described by the American Society for Microbiology and revised by the National Committee for Clinical Laboratory Standards $(12,13)$. This was defined as the lowestconcentration of the antibiotic to prevent visible growth of the bacteria. Pure antibiotic powders of ampicillin, chloramphenicol, gentamicin, cefuroxime, ciprofloxacin, tetracycline and amoxycillin-clavulanic acid were used to prepare doubling dilutions of the antibiotics in Mueller-Hinton agar (13). The concentrations to be tested were determined by the interpretative breakpoints as provided by NCCLS.E. coli ATCC 25922 was used to control for drug potency and growth of bacteria.

Pulsed-field gel electrophoresis (PFGE): PFGE was performed using the contour-clamped homogenous electric field (Chef DRII) apparatus from Bio-Rad Laboratories according to the procedures described earlier (14-15) in one per cent pulsed-field certified agarose in 5x TBE buffer for 40 hours at $200 \mathrm{~V}$ at a temperature of $14^{\circ} \mathrm{C}$ with the following modified pulse times: 1-10 seconds for ten hour, 3-28 seconds for ten hour, 3-35 seconds for five hour, and 5-70 seconds for fifteen hour, a gradient of $6.0 \mathrm{~V}$ per second and a 120 degrees switch angle. The gels were then stained with ethidium bromide, destained and photographed under UV illumination on a gel documentation system. The DNA size standards used were the bacteriophage lambda ladder ranging from $50 \mathrm{~kb}$ to $1,000 \mathrm{~kb}$ (BioRad).

\section{RESULTS}

Demographic data and other characteristics of the study subjects: The hotels sampled varied from low budget backpackers hotels to deluxe five star hotels. There were a total of 19 hotels sampled from Nairobi, and sixteen from Malindi and seven from Diani respectively. The demographic data and other characteristics of the study subjects are shown in Tables 2 and 3. The study subjects from whom EPEC and STEC were recovered ranged in age from 24 years to 50 years with a mean age of 32.6 and a standard deviation of 17.2 years. This was only slightly different than for the general study population (mean 32.5 years, SD of8.l and range 15-63years). These differences were not statistically significant $(p>0.05)$. The ratio of men to women mirrored that of the general population. Significantly more loose stools were associated with isolation of EPEC/STEC than with those from whom no pathogen was isolated $\left(X^{2}=67.76, p<0.001\right)$. The number of subjects who admitted to having used any form of antibiotic in the last 14 days was $2 / 13$ from whom EPEC/STEC were isolated who responded to the question on taking antibiotics. This, however, was not statistically significant $(p>0.1)$. Only two subjects responded to the question of sanitation disposal so this question could not be analysed. No enteroparasites were observed from the stool samples of subjects from whom EPEC/STEC were isolated.

Table 2

Age characteristics of the study subjects by study site

\begin{tabular}{lcccc}
\hline Variable & Nairobi & Malindi & Diani & Total \\
\hline Age range & $19-63$ & $15-56$ & $18-55$ & $15-63$ \\
Mean age & 30.4 & 20.0 & 28.7 & 28.2 \\
SD & 10.9 & 16.0 & 15.2 & 13.3 \\
Median age & 39.0 & 33.0 & 36.0 & 38.0 \\
IQR & $29.0-49.0$ & $25-42$ & $27-46$ & $27-49$ \\
Age not known & $51 /(5.8 \%)$ & $89(35.2 \%)$ & $46(17.6 \%)$ & $185(13.2 \%)$ \\
Males & $651(73.7 \%)$ & $199(78.7 \%)$ & $239(91.2 \%)$ & $1089(78.0 \%)$ \\
Females & $230(26.1 \%)$ & $54(21.7)$ & $23(8.8 \%)$ & $307(22.0 \%)$ \\
\hline Total & $885^{*}$ & 253 & 262 & 1399 \\
\hline
\end{tabular}

$\mathrm{SD}=$ Standard deviation

IQR- Inter-quartile range

*4 Sex not indicated 
Table 3

Demographic data and other characteristics of the food handlers from whom EPEC and STEC was isolated ( $n=1399)$

\begin{tabular}{|c|c|c|c|c|}
\hline Parameter & & $\mathrm{NPI}^{*}(\mathrm{n}=1316)$ & $\operatorname{EPEC~}(n=13)$ & P-value \\
\hline & Range & $15.0-63.0$ & $24.0-50.0$ & \\
\hline \multirow[t]{2}{*}{ Age (years) } & Mean & 32.5 & 32.6 & \\
\hline & SD & 8.1 & 17.2 & \\
\hline \multirow[t]{2}{*}{ Sex } & Males & $1021(77.6 \%)$ & $9 / 13(69.2 \%)$ & $X^{2}=0.51$ \\
\hline & Females & $295(22.4 \%)$ & $4 / 13(30.8 \%)$ & $\mathrm{p}>0.05$ \\
\hline \multirow[t]{10}{*}{ Stool Type } & Formed & $563(62.4 \%)$ & 0 & \\
\hline & Loose & $82(9.0 \%)$ & 10 & \\
\hline & Mucoid & $27(3.0 \%)$ & & \\
\hline & Semi-formed & $222(24.7 \%)$ & 1 & $X^{2}=67.76$ \\
\hline & Watery & $1(0.1 \%)$ & 0 & \\
\hline & & & & $\mathrm{p}<00.1$ \\
\hline & Mucoid/semi-formed & $1(0.1 \%)$ & 0 & \\
\hline & Loose/watery & $5(0.5 \%)$ & 0 & \\
\hline & Loose/mucoid/blood stained & $1(0.1 \%)$ & & \\
\hline & Not indicated & $1(0.1 \%)$ & 0 & \\
\hline \multirow{3}{*}{$\begin{array}{l}\text { Antibiotic use in } \\
\text { the last } 14 \text { days }\end{array}$} & Yes & $62 / 1316(4.7 \%)$ & $2 / 13$ & $X^{2}=1.87$ \\
\hline & No & $1254 / 1316(95.3 \%)$ & 0 & \\
\hline & & & & $\mathrm{p}>0.05$ \\
\hline \multirow[t]{4}{*}{ Water source } & Rain water/Borehole & $0 \quad(0.0 \%)$ & 0 & \\
\hline & Tap water & $447(80.8 \%)$ & 1 & $X^{2}=0.43$ \\
\hline & Borehole & $84(14.5 \%)$ & 0 & $\mathrm{p}>0.2$ \\
\hline & Well water & $5(0.9 \%)$ & & \\
\hline \multirow[t]{3}{*}{ Sanitation disposal } & Pit latrine & $282(49.6 \%)$ & 1 & \\
\hline & Flush toilet & $262(46.1 \%)$ & 1 & $X^{2}-0.006$ \\
\hline & Other & $25(4.4 \%)$ & 0 & $\mathrm{p}>0.2$ \\
\hline Parasites & & $31 / 1316(2.4 \%)$ & No O/C seen & \\
\hline
\end{tabular}

Incidence of EPEC and STEC and the respective virulence genes: A total of two STEC and 11 EPEC were isolated and the distribution of these is shown in Table 4 . None was isolated in Diani and only one EPEC was isolated in Malindi. The rest were all isolated from Nairobi samples. The incidence of EPEC and STEC combined was $1.4 \%$ in Nairobi and $0.4 \%$ in Malindi respectively. The overall incidence of EPEC and STEC combined for all the three study sites was found to be $0.9 \%$ and as a proportion of all the DEC it was $13 / 83(15.7 \%)$. The EPEC had the eae $A$ gene while the STEC expressed the at 2 and eae $A$ genes. One of the STEC was serotyped as 0159, but the other was non-serotypable. Of 11 EPEC, two were 0157 and one was 063 . Others were non-serotypable. The two 0157 isolates were from two separate five star hotels in Nairobi.

\section{Table 4}

Distribution of EPEC and STEC and the respective toxin genes by study site

\begin{tabular}{lcccc}
\hline Pathogen & $\begin{array}{c}\text { Nairobi } \\
(\mathrm{n}=885)\end{array}$ & $\begin{array}{c}\text { Malindi } \\
(\mathrm{n}=253)\end{array}$ & $\begin{array}{c}\text { Diani } \\
(\mathrm{n}=262)\end{array}$ & $\begin{array}{c}\text { Total } \\
(\mathrm{n}=1399)\end{array}$ \\
\hline STEC (stx2) & 2 & 0 & 0 & 2 \\
EPEC (eaeA) & 10 & 1 & 0 & 11 \\
\hline Total & 12 & 1 & 0 & 13 \\
\hline
\end{tabular}

Antibiotic resistance profiles of the isolates: Nine of the thirteen isolates were tested by use of the E-test MIC method. Resistance was seen against co-trimoxazole $(55.6 \%)$, chloramphenicol $(33.3 \%)$, ampicillin $(22.2 \%)$ and tetracycline $(22.2 \%)$. $\mathrm{MIC}_{90}$ was elevated above the resistance range for ampicillin, tetracycline and 
co-trimoxazole. However, the $\mathrm{MIC}_{50}$ and $\mathrm{MIC}_{90}$ of the other antibiotics were at low levels (Table 5). There were 11 resistance patterns with MDR being seen in six isolates $(6 / 13,46.2 \%)$. All the resistance types consisted of one isolate for each type. Only two isolates $(2 / 13,15.4 \%)$ were sensitive to all tested antibiotics. The two STECisolates showed resistance to ampicillin, co-amoxyclav, ciprofloxacin and tetracycline (amp, amc, cip, te) and ampicillin, cefuroxime, cefotaxime (amp, cxm, ctx) respectively.

Clonal relatedness of the isolated EPEC and STEC: The genetic relatedness among the EPEC/STEC isolates from food handlers working in tourist hotels in Kenya was determined by the use of pulsed-field electrophoresis method. The PFGE analysis revealed that eight EPEC and two STEC strains produced 11 distinct DNA fragment profiles. Each PFGE profile displayed several bands from below $50 \mathrm{~kb}$ to about $600 \mathrm{~kb}$ within the 50 to $1000 \mathrm{~kb}$ range (Figure 2). The cluster analysis of the PFGE profiles revealed that the ETEC tested belonged to two major genetic groups (Figure 3). Cluster one comprised seven isolates whereas cluster II consisted of three isolates. Isolates IC 107 and NSC05 did not reveal any bands.

Table 5

$M I C$ resistance range, $M I C_{50}$ and $M I C_{90}$ of the EPEC/STEC isolates

\begin{tabular}{lccccc}
\hline Antibiotic tested & $\begin{array}{c}\text { Resistant } \\
\text { No. }(\%)\end{array}$ & $\begin{array}{c}\text { MIC range } \\
(\mu \mathrm{g} / \mathrm{ml})\end{array}$ & $\begin{array}{c}\mathrm{MIC}_{50} \\
(\mu \mathrm{g} / \mathrm{ml})\end{array}$ & $\begin{array}{c}\mathrm{MIC}_{90} \\
(\mu \mathrm{g} / \mathrm{ml})\end{array}$ \\
\hline Chloramphenicol & 3 & 33.3 & $2-12$ & 4 & 8 \\
Co-amoxyclav & 0 & 0.0 & $2-16$ & 4 & 16 \\
Gentamicin & 0 & 0.0 & $0.5-1$ & 1 & 1 \\
Co-trimoxazole & 5 & 55.6 & $0.047 \geq 32$ & $>32$ & $>32$ \\
Ciprofloxacin & 0 & 0.0 & $0.012-0.023$ & 0.023 & 0.023 \\
Ampicillin & 2 & 22.2 & $2 \geq 256$ & 6 & $>256$ \\
Cefuroxime & 0 & 0.0 & $4-8$ & 6 & 8 \\
Tetracycline & 2 & 22.2 & $1-32$ & 2 & 32 \\
Cefotaxime & 0 & 0.0 & $0.064-0.5$ & 0.125 & 0.125 \\
\hline
\end{tabular}

Figure 2

PFGE patterns of the EPEC and STEC isolated from the food handlers Lane 1 and Lane 15 are Lambda DNA $50 \mathrm{~Kb}$ step molecular weight markers. Lane 2 to lane 14 represent isolates IC107, NSC05, WGC033, UT137, NAS60, WGC016, TB012, IC03107, IC136, NSC36, UT37, NAS36, and MLD014 respectively. Isolates TB012 and MLD014 are EAEC isolates used as controls. All the strains were different except strain numbers IC107 and NSC05 which showed 100\% similarity to each other. All the isolates tested above were from Nairobi

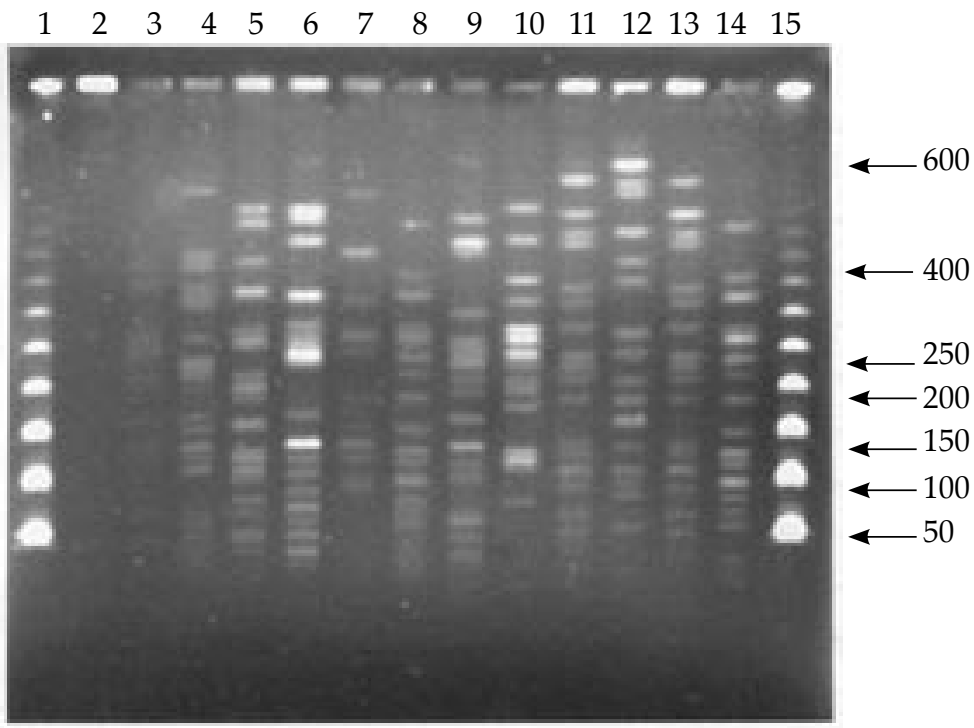




\section{Figure 3}

The dendrogram outlining the clonal relationship of the EPEC isolates. The genetic distance between isolates is shown on the scale

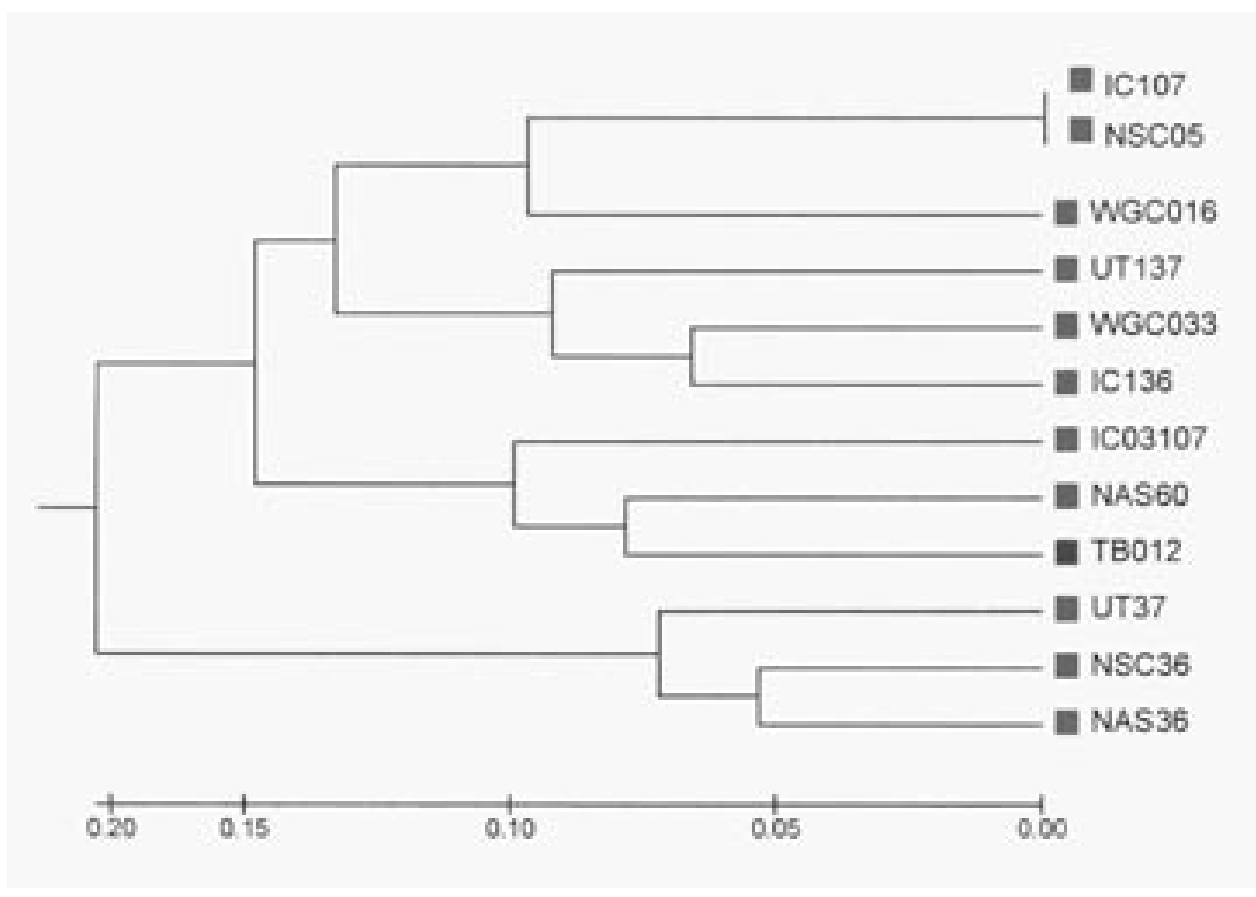

There were three sub-clusters in cluster 1 with very close genetic distance from each other. In cluster 2, there were two sub-clusters with one sub-cluster consisting of one isolate (UT37). The second subcluster consisted of two isolates, which were closely related with an equal genetic distance (NAS36 and NSC036).

\section{DISCUSSION}

STEC is an important cause of gastrointestinal disease in humans and which can result in life-threatening sequelae of haemolytic uremic syndrome (HUS) and thrombotic thrombocytopenic purpura (16). It has been suggested that STEC strains producing Shiga toxin type 2 encoded by the st $x 2$ gene is more virulent than st 1 type and it is more likely to result in HUS disease (16). In our study we obtained from diarrhoegenic stools twoSTEC strains that contained the stx 2 gene and hence could potentially have resulted in severe disease in the food handlers from whom they were isolated. An incidence of 13/1399 $(0.9 \%)$ was observed for the EPEC/STEC isolates in this study. Most of the isolates were from loose stools with only one being from semi-formed stool. These results are in agreement with other previous studies where theSTEC was either absent (17) or was at much lower proportion than the isolated EPEC (18).

In a study on the epidemiology of infectious diarrhoea in children in Kenya (19) the incidence of EPEC/STEC was found to be $8.8 \%$ whilein Taiwanese children it was $4 \%$ (20). In Nigeria EPEC was isolated from $1.6 \%$ of adult controls without diarrhoea and STEC from $20.4 \%$ of diarrhoea cases and $6.4 \%$ from controls. The isolation of STEC in Kenya is very rare with the first and only report being in 1996 (21). This is the second report of isolation of STEC in Kenya.

STEC produce potent toxins and cause a particularly severeform of disease; haemorrhagic colitis (HC). About $10 \%$ of patients with $\mathrm{HC}$ can go on to develop HUS, a life-threatening complication of STEC infection that is characterised by acute renal failure, haemolytic anaemia, and thrombocytopenia. These sequelae are particularly serious in young children and older people. On average, $2-7 \%$ of patients with HUS die, but in some outbreaks among the elderly, the mortality rate has been as high as $50 \%$ (22). The finding of STEC from the stools of food handlers has got major implications for food safety not only in TD butalso for the community at large. There is a likelihood of the spread of this very virulent pathogen to food consumers and the general community resulting from contamination of food and water. Currently there are no specific and sensitive biochemical tests that can be used to identify conclusivelyEPECandSTEC fromnon-toxigenicstrains of $E$. coli except for the non-sorbitol fermentation test for 0157 and serotyping. Rapid identification of EPEC and STEC is important for patient management and for prompt epidemiological investigations. The use of real-time PCR is an improvement in the classical PCR method and has scope for use in clinical microbiological laboratories. 
From the antibiotic susceptibility experiments high resistance rates were exhibited against ampicillin $22.2 \%$, tetracycline $22.2 \%$, chloramphenicol $33.3 \%$ and co-trimoxazole $55.6 \%$. In other work done in Kenya, Bii elal,(23) found resistance against tetracycline of $70.7 \%$, co-trimoxazole of $68.3 \%$ and to ampicillin at $65.9 \%$. Similar results were alsoobtained in studies from West Africa (24) whereanincreasing resistance to tetracycline from $34.9 \%$ to $100 \%$, resistance to sulphonamides from $25.4 \%$ to $74.3 \%$ and $30 \%$ to $78 \%$ against ampicillin between 1986 and 1998 was observed. Similarly, in a study of antibiotic resistance of faecal E. coli from healthy volunteers from eight developing countries (25), resistance to tetracycline was seen at $92 \%$ and to ampicillin of $89 \%$. There were 11 resistance types with MDR being seen in six isolates $(6 / 13,46.2 \%)$. All the resistance types consisted of one isolate each type. Only two isolates $(2 / 13,15.4 \%)$ were sensitive to all tested antibiotics. The high rate of untypability of the isolates might suggest that serotyping is not useful to detect diarrhoegenic $E$. coli. Genetic analysis might be necessary to detect diarrhoegenic E. coli. Cluster analysis of the PFGE profiles revealed heterogeneous EPEC and STEC spread in Kenya. This is the first report from sub-Saharan Africa on the isolation of EPEC 0157 and STEC from food handlers working in tourist hotels in Africa.

In resource poor settings especially, it is difficult to routinely test for diarrhoegenic E. coli and there is a scarcity of data from this region of the world. The use of basic isolation media, antibiotic susceptibility testing, real-time PCR and PFGE profiling has enabled the establishment of the status of carriage of EPEC and STEC by food handlers in Kenya. It should be emphasised that only a small population of food handlers was studied so the carriage rates may be different in the general population.

\section{ACKNOWLEDGEMENTS}

To the Director and the Laboratory staff of the Centre for Microbiology Research, who facilitated this work. This work was part of Doctor of Philosophy inMedical Microbiology degree work for J. O. Oundo at the Institute of Tropical Medicine and Infectious Diseases of the Jomo Kenyatta University, Nairobi and supported by the Kenya Medical Research Institute for his PhD studies. This work is published with the permission of Director, Kenya Medical Research Institute.

\section{REFERENCES}

1. DuPont, H. L., Steffen, R., Sack, D. A. L., et al. A randomised double-blind, parallel placebo (PBO)-controlled study of rifaximin (RFX) at 600 and $1200 \mathrm{mg} /$ day in the treatment of bacterial infectious diarrhoea in travellers. Rifaximin clinical compendium, 7 th Conference of the International
Society of travel Medicine, May 27-31,2001, Innsbruck, Austria.

2. Kovanda, J.S. Travellers' diarrhea: pathogenesis and management. 2000; Rev Med. Liege. 55: 492-499.

3. Gomi, H., Jiang, Z., Adachi, J. A., et al. In vitro antimicrobial susceptibility testing of bacterial enteropathogens causing travelers' diarrhoea in four geographic regions. Antimicrob. Agents. Chemother. 2001; 45: 212-216.

4. Jiang, Z. D., Lowe, B., Verenkar, M. P., et al. Prevalence of enteric pathogens among international travellers with diarrhea acquired in Kenya (Mombasa), India. (Goa), or Jamaica (Monte go Bay). J. Infect. Dis. 2002; 185: 497-502.

5. Steffen, R., Collard, F., Tornieporth, N., et al. Epidemiology, etiology, and impact of travellers' diarrhoea in Jamaica. JAMA. 1999; 281: 811-817.

6. Ombui, J.N., Kagiko, M.M. and Arimi, S.M. Foodborne diseases in Kenya. East Afr. Med. J. 2001; 78: 40-44.

7. Lindqvist, R., Andersson, Y., Lindback, J., et al. A one-year study of food-borne illnesses in the municipality of Uppsala, Sweden. Emerg. infect. Dis. 2001; 7: 588-590.

8. Tauxe, R. V. Food safety and irradiation: protecting the public from food infections. Emerg. infect. Dis. 2001; 7: 516-521.

9. (http//www.cbs.go.ke/ census/1999.html).

10. (http://www.citypopulation.de/kenya.html)

11. lijima, Y., N. T. Asako, M. Aihara and K. Hayashi. Improvement in the detection rate of diarrhoegenic bacteria in human stool specimens by a rapid realtime PCR assay. J. Med. Microbiol. 2004; 53: 617-622.

12. Isenberg, H. D. Clinical Microbiology Procedures Handbook. American Society for Microbiology. Washington D. C. USA. 1992; 1: 5.1.1

13. NationalCommittee for Clinical LaboratoryStandards (NCCLS). Methods for dilution antimicrobial susceptibility tests for bacteria that grow aerobically. Approved standard M7-A3. National Committee for Clinical Laboratory Standards, Villanova, Pa. 2002; 17(2).

14. Albert, M. J., N. A. Bhuiyan, K. A. Talukder, et al. Phenotypic and genotypic changes in Vibrio cholerae 0139 Bengal. J. Clin. Microbiol. 1997; 35:2588-2592.

15. Talukder, K. A. Dutta, D. K. and Albert, M. J. Evaluation of pulsedfield gel electrophoresis for typing of Shigella dysenteriae type 1. J. Med. Microbiol. 1999; 48: 781-784.

16. Paton, A. W. and Paton, J. C. Detection and characterization of Shiga toxigenic Escherichia coli by using multiplex PCR assays for stx1, stx2 eaeA, enterohemorrhagic E. coli hylA, rfb 0111 and rfb 0157 J. Clin. Microbiol. Rev. 1998; 598- 602.

17. Nataro, J. P. and Kaper J. B. Diarrheagenic Escherichia coli. Clinical Microbiol. Rev. 1998; 11: 142-201.

18. Vila, J., M. Vargas, C. Casalas, H. et al. Antimicrobial resistance of diarrhegenic Escherichia coli isolated from children under the age of five years from Ifakara, Tanzania. Antimicrob. Agents. Chemother. 1999; 43: 3022-3024.

19. Saidi, S.M., Iijima, Y. Sang, W.K. etal. Epidemiological study on infectious diarrhoeal diseases in children in a coastal rural area in Kenya. Microbiol. Immunol. 1997; 41: 773-778. 
20. Hsueh, P. R. Liaw, S. J. Ho, W. et al. Genetic detection of diarrhegenic Escherichia coli isolated from children with sporadic diarrhoea. J. Microbiol. Immunol. Infect. 2004; 37: 327-334

21. Sang, W.K., Saidi, S.M., Yamamoto, H., et al. Haemorrhagic colitis due to Escherichia coli 0157:H7 in Kenya. J. Trop. Pediatr. 1996; 42: 118-119.

22. ReillyA.Preventionand controlofenterohaemorrhagic Escherichia coli (EHEC) infections: memorandum from a WHO meeting. WHO Consultation on Prevention and Control of Enterohaemorrhagic Escherichia coli (EHEC) Infections. Bull. World Hlth Org. 1998; 76: 245-55.
23. Bii, C. C., Taguchi, H. Ouko, T. T. et al. Detection of virulence-related genes by multiplex PCR in multidrug-resistant diarrhoegenic Escherichia coli isolates from Kenya and Japan. Epidemiol. Infect. 2005; 133: 627-633.

24. Okeke, I. N., Ojo, O. Laminkara, A. and Kaper., J. B. Etiology of acute diarrhea in adults in southwestern Nigeria. J. Clin. Microbiol. 2003; 4525-4530.

25. Nys,S.,Okeke,I.N.Kariuki,S.etal. Antibiotic resistance of faecal Escherichia coli from healthy volunteers from eight developing countries. J. Antimicrob. Chemother. 2004; 54: 952-955. 